\title{
Inaccurate Early Assessment of Neurological Severity in Head Injury
}

\author{
NINO STOCCHETTI, ${ }^{1}$ FRANCESCA PAGAN, ${ }^{1}$ EMILIANA CALAPPI, ${ }^{1}$ \\ KATIA CANAVESI, ${ }^{1}$ LUIGI BERETTA, ${ }^{2}$ GIUSEPPE CITERIO, ${ }^{3}$ \\ MANUELA CORMIO, ${ }^{3}$ and ANGELO COLOMBO ${ }^{1}$
}

\begin{abstract}
Intubation, which requires sedation and myorelaxants, may lead to inaccurate neurological evaluation of severely head-injured patients. Aims of this study were to describe the early clinical evolution of traumatic brain injured (TBI) patients admitted to intensive care unit (ICU), to identify cases of over-estimated neurological severity, and to quantify the risk factors for this over-estimation. A total of 753 TBI patients consecutively admitted to ICU of three academic neurosurgical hospitals (NSH) were assessed. Cases whose severity was potentially over-estimated were identified by four criteria and indicated as "mistakenly severe" (MS): (1) no surgical intracranial masses; (2) could not follow commands at neurological assessment; (3) were dismissed from the ICU in $\leq 3$ days to a regular ward; and (4) had regained the ability to obey commands. A total of 675 patients were intubated and/or sedated-paralyzed at the post-stabilization evaluation. In all, 304 patients had surgically treated intracranial masses. Among the 449 non-surgical cases, 58 patients fulfilling the criteria for MS were identified. The main features distinguishing MS from truly severe cases were younger age, higher Glasgow Coma Scale (GCS) score at all time points, Marshall classification of Computerized Tomographic (CT) scan mostly Diffuse Injury I and II, fewer pupillary abnormalities, and a lower frequency of hypoxia, hypotension, and extra-cranial injuries. In a certain proportion of non-surgical TBI patients, mostly intubated and sedated, neurological examination is difficult and severity can be over-estimated. Risk factors for this inaccurate evaluation can be identified, and clinical decisions should be based on further examination.
\end{abstract}

Key words: Glasgow Coma Scale; head injury; neurological assessment; outcome; sedation

\section{INTRODUCTION}

$\mathbf{M}$ ANAGEMENT of head-injured patients at the accident scene has changed strikingly in the last 20 years. The importance of adequate oxygenation and airway protection is now recognized (Chesnut et al., 1993; Maas et al., 1997; Manley et al., 2001), and as a consequence, intubation is more frequent. Guidelines recommend intubation at the accident scene under sedation and paralysis to avoid deleterious rises of intracranial pressure.

This has meant that a significant number of traumatic brain injuries (TBI) arrive at the hospital already sedated

\footnotetext{
${ }^{1}$ Neuroscience Intensive Care, Department of Anesthesia and Intensive Care, Ospedale Policlinico IRCCS, Milano University, Milano, Italy.

${ }^{2}$ Department of Anesthesia and Intensive Care, Ospedale S. Raffaele, Milano, Italy.

${ }^{3}$ Department of Anesthesia and Intensive Care, Ospedale S. Gerardo, Monza, Italy
} 


\section{STOCCHETTI ET AL.}

and intubated, sometimes paralyzed, so that neurological evaluation becomes problematic. The patient's verbal response is altered or abolished by the endotracheal tube, and sometimes facial, palpebral, or ocular injuries can interfere with eye opening and evaluation of pupils. The loss or a limitation of motor response is difficult to interpret, because any impairment of motor activity may be due either to deterioration or to the effects of sedation.

These limitations notwithstanding, a precise assessment is indispensable, both for decision making (medical and surgical treatment, intracranial pressure [ICP] monitoring, ICU admission) and for prognosis. Additional reasons for reliable evaluation are clinical trials, which impose strict inclusion criteria.

The aims of this study were as follows:

1. To describe the early clinical course of TBI patients admitted to intensive care

2. To identify cases in whom the neurological severity was most probably over-estimated

3 . to quantify the risk factors contributing to this overestimation

\section{MATERIALS AND METHODS}

Patients admitted consecutively to three neurosurgical hospitals (NSH) from January 1, 1997 to December 31, 2000 were prospectively studied. The inclusion criteria were as follows:

- Admission because of head trauma, with or without extra-cranial injuries

- Brain injury severity requiring "per se" intensive care, regardless of associated extra-cranial injuries

- Time from trauma to arrival at the NSH $<12 \mathrm{~h}$

- At least two neurological evaluations at different time-points in the early phases after injury

- Age of $\geq 2$ years

Clinical and demographic data regarding the pre-hospital phase and various aspects of in-hospital treatment, together with an assessment of outcome six months after the trauma, were entered in a computerized data base (Citerio et al., 2000). The collection and analysis of anonymized clinical data, specifically for this data base, were approved by the local Ethical committee.

The three NSH act as referral centers for an area of approximately 3 million inhabitants, with the highest density of traffic in Italy. Clinical and instrumental parameters were recorded at three time points: before reaching the NSH, at admission to the NSH and after stabilization in the NSH. In some cases reliable documentation concerning the pre-NSH phase was not available, but at least two repeated GCS ratings were documented for all cases (Teasdale and Jennett, 1974).

The first evaluation in the field was provided by an emergency doctor, usually a graduate in anesthesia. Together with a neurological examination, secondary injuries such as hypoxia and hypotension were noted. Hypoxia was coded as "suspected," when based on clinical findings such as cyanosis, or "definite," when arterial saturation was measured by a pulse oxymeter. Hypotension was defined as an arterial systolic pressure of $<95 \mathrm{~mm}$ $\mathrm{Hg}$. The admission and post-stabilization evaluations were usually done by a team including a neurosurgeon and an intensivist.

On arrival patients were evaluated, stabilized and a CT scan was done for prompt identification (and urgent evacuation) of surgical masses. CT scan was scored according to the Traumatic Coma Data Bank classification (Marshall et al., 1991). All patients were managed according to published guidelines (Maas et al. 1997).

Patients were divided into four groups (Fig. 1):

- Surgical cases: Patients with an intracranial lesion that was subsequently evacuated

- Mild/moderate TBI: Nonsurgical patients able to obey commands (motor component of the GCS =6) at every neurological assessment

- Really severe (RS) patients: All the remaining nonsurgical cases that could not follow commands at least at one point of neurological assessment and not fulfilling the mistakenly severe criteria

- Mistakenly severe (MS) patients: Cases in whom severity was probably overestimated

Therefore MS patients were identified according to the following criteria:

- No surgical intracranial masses

- Could not follow commands at least at one point of neurological assessment

- Transferred from the ICU in $\leq 3$ days to a regular ward

- Obeyed commands at discharge from the ICU

Outcome was assessed at 6 months after injury using a structured interview according to the Glasgow Outcome Scale (Wilson et al., 1998).

\section{Statistical Analysis}

We followed several steps to identify the parameters associated with the MS cases:

1. A bivariate analysis was conducted to select parameters significantly more frequent in the MS group. As- 


\section{INACCURATE EARLY NEUROLOGICAL ASSESSMENT IN HEAD INJURY}

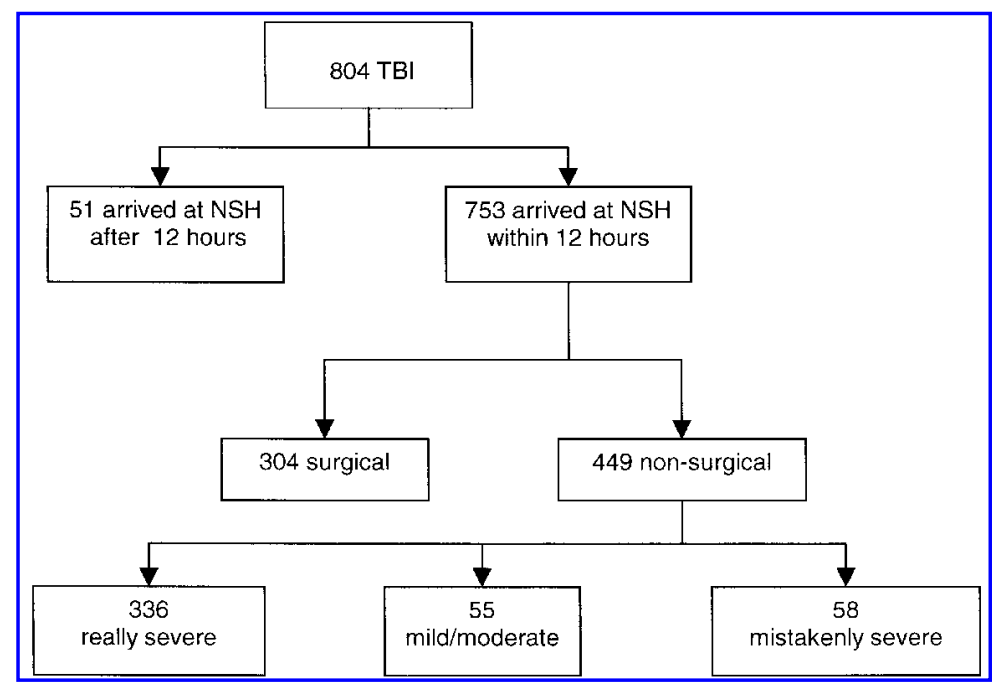

FIG. 1. Division of cases extracted from the data base.

sociations of categorical independent variables with MS were assessed with chi-squared tests. Variables were eligible for entry into a multiple logistic regression model if they were significantly associated with MS at a $p$ value of $<0.05$.

2. A multivariate analysis was done by logistic regression: using the method of maximum likelihood we calculated estimated coefficients and their standard errors. Variables were introduced into the model one at a time based on likelihood ratio tests until a significant $p$ value was retained.

3. When all the significant variables had been entered in the multivariate model, the calibration was measured using the Hosmer-Lemeshow goodness-of-fit test (Lemeshow et al., 1993), which assesses the degree of correspondence between the model's estimated probabilities of being scored as MS and the observed MS cases.

4. The discrimination was assessed using the area under the receiver operating characteristic (ROC) curve to see how well the model distinguished MS patients from the others.

All calculations were done using SAS System software, version 8 (SAS Institute Inc., Cary, NC).

\section{RESULTS}

\section{General Findings}

Out of 804 cases admitted during the study period, 753 fulfilled the inclusion criteria. They were 564 males and 189 females, with a median age of 35.5 years (range,
2-93 years). Extra-cranial lesions were present in 426 patients.

Complete CT scan documentation was available for 751 patients: 369 had an intracranial mass, and in 310 the mass was larger than $25 \mathrm{~mL}$.

Hypoxia was clinically suspected at the accident scene in 91 cases (12\%) and measured by pulse oxymeter, recording a value lower than $90 \%$, in 112 patients (15\%).

On arrival at the $\mathrm{NSH}$, arterial desaturation was detected by pulse oxymetry in 28 cases $(4 \%)$; stabilization was successful in the majority of cases, so that only five patients $(1 \%)$ were still desaturated at the last neurological evaluation considered in this study.

A total of 490 patients $(65 \%)$ arrived already intubated.

In all, 422 patients were admitted directly to the NSH, and 331 were accepted in a referring hospital and subsequently transferred. The median interval between trauma and arrival at the NSH was $91 \mathrm{~min}$; it was $48 \mathrm{~min}$ for direct admissions and 210 min for patients referred from another hospital. Data of the three components of the GCS are summarized in Table 1.

On arrival, 427 patients were sedated; 247 had been given myorelaxants with sedative drugs. Eight cases had only myorelaxants as documented medication prior to arrival. In another 99 cases, endotracheal intubation had been done before arrival at the $\mathrm{NSH}$, but there was no record of anesthesia or sedation. A total of 534 patients were intubated and/or sedated-paralyzed at this point.

A complete description of the three components of the GCS was available for all 753 patients on admission (Table 1).

In order to stabilize or improve oxygenation, 141 cases were intubated after the first in-hospital evaluation. Us- 


\section{STOCCHETTI ET AL.}

ing the definitions given above, we identified 304 surgical cases, 55 mild/moderate TBI, 58 patients fulfilling the criteria for "mistakenly severe," and 336 "really severe" patients. This subdivision is illustrated in Figure 1.

Among the 304 surgical cases, 192 (63\%) were already intubated or under the effect of sedative drugs on arrival at the NSH; 84 additional patients were intubated on admission.

The CT scan identified 119 subdural hematomas, 91 extradural, and 94 with contusions. Basal cisterns were compressed or absent in 206 cases (68\%).

\section{Features of "Really Severe" Cases}

A total of 336 patients were classified as RS. Their median age was 33 years (range, 3-88 years). CT scan showed 292 cases (87\%) with Diffuse Injury greater than I or non-evacuated mass lesions. A great number of cases showed a motor response of withdrawal or less at every time point: there were 173 at pre-admission (out of 298 tested, 58\%), 163 on admission (out of 336, $49 \%$ ), and 163 post-stabilization (out of $336,49 \%$ ).

Most cases were intubated $(269 / 336,80 \%)$ and 224 were sedated and/or paralyzed $(224 / 336,67 \%)$, so that a total of $286(85 \%)$ cases had intubation and/or sedation.

Eye opening, spontaneously or in response to stimuli, was rare at all the time points and pupillary abnormalities were frequent. Details are given in Tables 2 and 3.

\section{Features of "Mistakenly Severe" Cases}

Fifty-eight cases were identified as MS. Their median age was 26 years (range, 2-81 years). CT scan showed almost exclusively Diffuse Injury I (19/58, 33\%) or II (34/58, 59\%).

According to definition, at some examination point, all cases did not obey commands: there were 36 at pre-admission (out of 47 tested, $77 \%$ ), on admission 47 (out of
$58,81 \%$ ), and post-stabilisation 39 (67\%). The majority of cases localized the painful stimulus at every time point. Motor response was absent only in two patients at the accident scene, two on admission, and one post-stabilization.

The verbal response was absent in a large proportion of cases: at the accident scene no verbal response was elicited in 27 cases (out of 47 tested, $57 \%$ ), on admission in 49 cases (out of 58,84\%) and post-stabilization in 47 $(81 \%)$.

Most cases were intubated $(49 / 58,84 \%)$ and 40 were sedated and/or paralysed $(40 / 58,69 \%)$, so that a total of $51(88 \%)$ cases had intubation and/or sedation.

Eye opening, spontaneously or in response to stimuli, was recorded at the accident scene in 24 cases (out of 46 tested, 52\%), on admission in 24 cases (out of 58, 41\%) and post-stabilization in $35(60 \%)$. The GCS total score was $\leq 8$ in 23 cases at the accident scene (out of $48,48 \%$ ), $37(64 \%)$ on admission and $30(52 \%)$ post-stabilization. Pupillary abnormalities were rare.

One case still had severe hypotension when stabilization was attempted. At the accident scene, six cases had either suspected or documented hypoxia; hypotension was measured in 10 patients. Two patients had both hypoxia and hypotension. Extra-cranial lesions were present in 32 patients $(55 \%)$.

\section{Distinctive Features of "Mistakenly Severe" Compared to "Really Severe" Cases: Bivariate and Logistic Regression Analysis}

The two groups were compared in two steps. First, the differences were analysed at the three time points for repeatedly assessed parameters, such as GCS, or once for data such as extra-cranial injuries. The results are shown in Tables 2 and 3. Second, the GCS and pupillary data for the post-stabilization phase and the other parameters which were significantly different between the MS and RS were entered in the logistic regression model. This analysis (Table 4) identified four parameters as indepen-

Table 1. Neurological Evaluation at Three Time Points:

At the Accident Scene, on Admission, and Post-Stabilization

\begin{tabular}{|c|c|c|c|c|c|c|c|c|c|}
\hline & \multicolumn{3}{|c|}{ GCSm } & \multicolumn{3}{|c|}{$G C S v$} & \multicolumn{3}{|c|}{ GCSe } \\
\hline & 6 & $5-4$ & $3-1$ & 5 & $4-2$ & 1 & 4 & $3-2$ & 1 \\
\hline Accident scene & $\begin{array}{c}157 / 641 \\
(24 \%)\end{array}$ & $\begin{array}{c}288 / 641 \\
(45 \%)\end{array}$ & $\begin{array}{c}196 / 641 \\
(31 \%)\end{array}$ & $\begin{array}{l}78 / 640 \\
(12 \%)\end{array}$ & $\begin{array}{c}166 / 640 \\
(26 \%)\end{array}$ & $\begin{array}{c}396 / 640 \\
(62 \%)\end{array}$ & $\begin{array}{c}139 / 638 \\
(22 \%)\end{array}$ & $\begin{array}{c}137 / 638 \\
(21 \%)\end{array}$ & $\begin{array}{c}362 / 638 \\
(57 \%)\end{array}$ \\
\hline Admission & $\begin{array}{c}136 / 753 \\
(18 \%)\end{array}$ & $\begin{array}{c}369 / 753 \\
(49 \%)\end{array}$ & $\begin{array}{c}248 / 753 \\
(33 \%)\end{array}$ & $\begin{array}{c}45 / 753 \\
(6 \%)\end{array}$ & $\begin{array}{l}88 / 753 \\
(12 \%)\end{array}$ & $\begin{array}{c}620 / 753 \\
(82 \%)\end{array}$ & $\begin{array}{c}90 / 753 \\
(12 \%)\end{array}$ & $\begin{array}{c}158 / 753 \\
(21 \%)\end{array}$ & $\begin{array}{c}505 / 753 \\
(67 \%)\end{array}$ \\
\hline Post-stabilization & $\begin{array}{c}161 / 753 \\
(21 \%)\end{array}$ & $\begin{array}{c}361 / 753 \\
(48 \%)\end{array}$ & $\begin{array}{c}231 / 753 \\
(31 \%)\end{array}$ & $\begin{array}{c}53 / 753 \\
(7 \%)\end{array}$ & $\begin{array}{c}64 / 753 \\
(9 \%)\end{array}$ & $\begin{array}{c}636 / 753 \\
(84 \%)\end{array}$ & $\begin{array}{c}106 / 753 \\
(14 \%)\end{array}$ & $\begin{array}{c}171 / 753 \\
(23 \%)\end{array}$ & $\begin{array}{c}476 / 753 \\
(63 \%)\end{array}$ \\
\hline
\end{tabular}

GCSm, GCSv, GCSe: motor, verbal and eye components of the Glasgow Coma Scale. 


\section{INACCURATE EARLY NEUROLOGICAL ASSESSMENT IN HEAD INJURY}

Table 2. Differences between "Mistakenly Severe" and "Really Severe"

Patients Based on the CT Scan and the Neurological Evaluation

\begin{tabular}{|c|c|c|c|}
\hline Feature & Mistakenly severe & Really severe & $\mathrm{p}$ value $\left(\chi^{2}\right)$ \\
\hline \multicolumn{4}{|l|}{ CT scan } \\
\hline Diffuse injury I-II & $53 / 58(92 \%)$ & $184 / 335(55 \%)$ & \multirow[t]{3}{*}{$<0.0001^{\mathrm{a}}$} \\
\hline Diffuse injury III-IV & $3 / 58(5 \%)$ & $92 / 335(27 \%)$ & \\
\hline Nonevacuated mass lesions & $2 / 58(3 \%)$ & $59 / 335(18 \%)$ & \\
\hline \multicolumn{4}{|l|}{ Pre-NSH } \\
\hline GCS m & & & \\
\hline$<5$ & 9/47 (19\%) & $173 / 298(58 \%)$ & \multirow[t]{2}{*}{$<0.0001$} \\
\hline$\geq 5$ & $38 / 47(81 \%)$ & $125 / 298(42 \%)$ & \\
\hline \multicolumn{4}{|l|}{ GCS v } \\
\hline $1-2$ & $32 / 47(68 \%)$ & $264 / 297(89 \%)$ & \multirow[t]{2}{*}{$\leq 0.0001$} \\
\hline$\geq 3$ & $15 / 47(32 \%)$ & $33 / 297(11 \%)$ & \\
\hline \multicolumn{4}{|l|}{ GCS e } \\
\hline 1 & $22 / 46(48 \%)$ & $214 / 296(72 \%)$ & \multirow[t]{2}{*}{0.0008} \\
\hline$\geq 2$ & $24 / 46(52 \%)$ & $82 / 296(28 \%)$ & \\
\hline \multicolumn{4}{|l|}{ Pupils } \\
\hline Normal & $38 / 47(81 \%)$ & $194 / 304(64 \%)$ & \multirow[t]{2}{*}{0.0217} \\
\hline Abnormal & 9/47 (19\%) & $110 / 304(36 \%)$ & \\
\hline \multicolumn{4}{|l|}{ Admission } \\
\hline GCS m & & & \multirow{3}{*}{$<0.0001$} \\
\hline$<5$ & $10 / 58(17 \%)$ & $163 / 336(49 \%)$ & \\
\hline$\geq 5$ & $48 / 58(83 \%)$ & $173 / 336(51 \%)$ & \\
\hline \multicolumn{4}{|l|}{ GCS v } \\
\hline $1-2$ & $50 / 58(86 \%)$ & $326 / 336(97 \%)$ & \multirow[t]{2}{*}{0.0003} \\
\hline$\geq 3$ & $8 / 58(14 \%)$ & $10 / 336(3 \%)$ & \\
\hline \multicolumn{4}{|l|}{ GCS e } \\
\hline 1 & $34 / 58(59 \%)$ & $255 / 336(76 \%)$ & \multirow[t]{2}{*}{0.006} \\
\hline$\geq 2$ & $24 / 58(41 \%)$ & $81 / 336(24 \%)$ & \\
\hline \multicolumn{4}{|l|}{ Pupils } \\
\hline Normal & $47 / 56(84 \%)$ & $230 / 323(71 \%)$ & \multirow[t]{2}{*}{0.0475} \\
\hline Abnormal & $9 / 56(16 \%)$ & $93 / 323(29 \%)$ & \\
\hline \multicolumn{4}{|l|}{ Post-stabilization } \\
\hline GCS m & & & \\
\hline$<5$ & $6 / 58(10 \%)$ & $163 / 336(49 \%)$ & \multirow[t]{2}{*}{$<0.0001$} \\
\hline$\geq 5$ & $52 / 58(90 \%)$ & $173 / 336(51 \%)$ & \\
\hline \multicolumn{4}{|l|}{ GCS v } \\
\hline $1-2$ & $47 / 58(81 \%)$ & $328 / 336(97 \%)$ & \multirow[t]{2}{*}{$<0.0001$} \\
\hline$\geq 3$ & $11 / 58(19 \%)$ & $8 / 336(3 \%)$ & \\
\hline \multicolumn{4}{|l|}{ GCS e } \\
\hline 1 & $23 / 58(40 \%)$ & $249 / 336(74 \%)$ & \multirow[t]{2}{*}{$<0.0001$} \\
\hline$\geq 2$ & $35 / 58(60 \%)$ & $87 / 336(26 \%)$ & \\
\hline \multicolumn{4}{|l|}{ Pupils } \\
\hline Normal & $49 / 55(89 \%)$ & $222 / 309(72 \%)$ & 0.0069 \\
\hline Abnormal & $6 / 55(11 \%)$ & $87 / 309(28 \%)$ & \\
\hline
\end{tabular}

Pupils abnormal, unilaterally or bilaterally dilated and not reacting to light.

aThe chi-square test was calculated assessing the differences between the diffuse injury I-II group and all other CT scan diagnoses.

dently associated with the probability of MS (age, CT scan classification, motor and verbal components of the GCS).

The CT scan diagnosis of Diffuse Injury I-II and the verbal component of the GCS (patients capable at least of pronouncing words) were the most predictive of MS. The verbal component of the GCS had an odds ratio of 6.4 , meaning that a patient with a score of at least 3 would 


\section{STOCCHETTI ET AL.}

Table 3. Differences between "Mistakenly Severe" and "Really Severe" Patients Concerning Age, Clinical Features, and Interventions

\begin{tabular}{|c|c|c|c|}
\hline Feature & Mistakenly severe & Really severe & $\mathrm{p}$ value $\left(\chi^{2}\right)$ \\
\hline \multicolumn{4}{|c|}{ Age (years) } \\
\hline$<40$ & $46 / 58(79 \%)$ & $200 / 336(60 \%)$ & \multirow[t]{2}{*}{0.0034} \\
\hline$\geq 40$ & $15 / 58(21 \%)$ & $136 / 336(40 \%)$ & \\
\hline \multicolumn{4}{|l|}{ Intubation } \\
\hline Yes & $49 / 58(84 \%)$ & $269 / 336(80 \%)$ & \multirow[t]{2}{*}{0.41} \\
\hline No & $9 / 58(16 \%)$ & $67 / 336(20 \%)$ & \\
\hline \multicolumn{4}{|l|}{ Drugs } \\
\hline Yes & $40 / 58(69 \%)$ & $224 / 336(67 \%)$ & \multirow[t]{2}{*}{0.649} \\
\hline No & $18 / 58(31 \%)$ & $112 / 336(33 \%)$ & \\
\hline \multicolumn{4}{|c|}{ Hypotension } \\
\hline Yes & $10 / 58(17 \%)$ & $119 / 335(36 \%)$ & \multirow[t]{2}{*}{0.0047} \\
\hline No & $48 / 58(83 \%)$ & $216 / 335(64 \%)$ & \\
\hline \multicolumn{4}{|l|}{ Hypoxia } \\
\hline Yes & $6 / 58(10 \%)$ & $126 / 335(38 \%)$ & \multirow[t]{2}{*}{0.0001} \\
\hline No & $52 / 58(90 \%)$ & $209 / 335(62 \%)$ & \\
\hline \multicolumn{4}{|c|}{ Extra-cranial lesions } \\
\hline Yes & $32 / 58(55 \%)$ & $232 / 336(69 \%)$ & \multirow[t]{2}{*}{0.0248} \\
\hline No & $26 / 58(45 \%)$ & $104 / 336(31 \%)$ & \\
\hline
\end{tabular}

be 6.4 times as likely to be MS than patient not having that score, controlling simultaneously for the other variables in the model. It must be noted, however, that the verbal response was fully testable only in nine MS patients, since 49 were intubated. In three intubated cases, however, the assessor evaluated a verbal response, assigning one a score of 2 , and two a score of 3 . A hypothetical patient with all four features-younger than 40 years, with a GCS motor of $>4$, etc.-would have a $75 \%$ probability of being MS, while a non-surgical case with none of these features will have an 8/1000 chance of being MS.

The model was well calibrated, as indicated by the Hosmer-Lemeshow goodness-of-fit test $(p=0.75)$, in which a high $p$ value indicates that the model is per- forming well, in other words, that there is not a wide discrepancy between observed and expected cases.

The area under the ROC curve was 0.808 , indicating that the model discriminated well between RS and MS.

\section{Discharge from the ICU and Outcome}

The mean length of stay (LOS) in the ICU was $8.7 \pm$ 8.6 days (median, 6 days). Restricting the analysis to survivors, the mean LOS was $10.3 \pm 8.8$ days (median, 8 days). Reflecting the selection criteria, the MS cases had a very short stay: 21 (36\%) were discharged after only 1 day of intensive care. Surgical cases had a LOS of $8.6 \pm$ 8.6 days (median, 6 days), while patients classified as RS stayed in the ICU $10.7 \pm 8.9$ days (median, 8.5 days).

Table 4. Estimated Logistic Regression Coefficients $(\beta)$,

Estimated Standard Errors (SE), Estimated Odds Ratios,

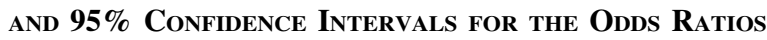

\begin{tabular}{lrc}
\hline Variable & $\beta(S E)$ & $\begin{array}{c}\text { Estimated odds ratio } \\
\text { (95\% confidence interval) }\end{array}$ \\
\hline Constant & $-4.8955(0.655)$ & NA \\
Age $<40$ years & $0.9119(0.382)$ & $2.5(1.2-5.3)$ \\
CT scan DI I-II & $1.7312(0.513)$ & $5.6(2.1-15.4)$ \\
GCSm $\geq 5$ & $1.4314(0.469)$ & $4.2(1.7-10.5)$ \\
GCSv $\geq 3$ & $1.8584(0.540)$ & $6.4(2.2-18.5)$ \\
\hline
\end{tabular}

NA, not applicable; DI, diffuse injury. 


\section{INACCURATE EARLY NEUROLOGICAL ASSESSMENT IN HEAD INJURY}

Forty-five patients were lost at 6 months follow-up, so outcome was assessed in 708 cases. Mortality was 30\% (214), vegetative status persisted in 19 cases (3\%), severe disability in $80(11 \%)$, and moderate disability persisted in 107 patients $(15 \%)$; a total of 288 patients $(41 \%)$ achieved a good recovery. The outcome was therefore favorable in $56 \%$ of cases.

Table 5 reports the outcome in the different groups. As expected, outcome was significantly worse for surgical and RS patients than the others $(p<0.0001)$. One hundred and thirty-seven surgical cases (48\%) and 171 RS $(53 \%)$ achieved a favorable outcome. A total of 42 mild/moderate $(86 \%)$ and 45 MS cases $(94 \%)$ had a favorable outcome. The only MS patient with a GOS 1 died because of chronic active hepatitis in the months after injury, following discharge from the NSH.

\section{DISCUSSION}

Respiratory failure is frequent in the early phases after head injury. When measured early, directly at the accident scene, hypoxia, defined as an arterial hemoglobin oxygen saturation of $<90 \%$, has been reported in $54 \%$ and airway obstruction in $44 \%$ of 50 cases rescued by helicopter (Stocchetti et al., 1996). At the time of arrival in hospital, hypoxemia, defined as arterial oxygen partial pressure $\left(\mathrm{PaO}_{2}\right)$ of $<60 \mathrm{~mm} \mathrm{Hg}$ in blood gas analysis, was present in $18 \%$ of 699 patients in the Traumatic Coma Data Bank series (Chesnut et al., 1993), and more recently, arterial desaturation after admission was found in 38\% of 107 TBI (Manley et al., 2001). In our series, hypoxia was suspected or confirmed by pulse oxymetry before hospital admission in one quarter of the cases.

Since airway management is necessary to counteract hypoxia, intubation plus artificial ventilation are part of the first treatment of head-injured patients; this is accepted in both American and European guidelines (The
Brain Trauma Foundation, 2000; Maas et al., 1997). Field intubation seems associated with significantly enhanced survival in TBI, with a reduction in mortality from $50 \%$ to $23 \%$ in patients with isolated severe head injury (Winchell and Hoyt, 1997). In our series, respiratory assistance, intubation, and ventilation were effective in correcting hypoxia, as suggested by the larger number of patients $(203 / 753,27 \%)$ who experienced hypoxia, either suspected or measured, at the accident scene, in comparison to $4 \%$ on arrival at the NSH and $1 \%$ post-stabilization.

Better oxygenation and protection of the airways, however, are achieved at the price of interventions-such as intubation, sedation, and sometimes paralysis - that may mask neurological responses and mislead the evaluation. Verbal responses are impeded by endotracheal intubation, and eye opening is one of the first activities lost by sedation, when not already hampered by palpebral injuries.

When myorelaxants are injected at full doses, motor activity is completely abolished; subsequently, as the plasma concentration drops, incomplete paralysis follows and the motor response can become very difficult to classify. For example a patient who, once cleared of anesthetics and myorelaxants, can obey orders or localize the painful stimulus might be misinterpreted either as not moving at all or as showing abnormal flexion.

Interventions interfering with the neurological evaluation are quite frequent. A total of 534 patients arrived at the NSH intubated and/or sedated and paralyzed; 141 cases were intubated afterwards, so that $90 \%$ of cases $(675 / 753)$ were evaluated post-stabilization in the presence of potential confounding factors.

However, early, repeated, and reliable neurological assessments are essential. Precise assessment, and the demonstration of improvement or deterioration, is necessary for planning surgical operations, for ICP monitoring, and for further medical treatment. Accurate eval-

Table 5. Six-Month Outcome According to the Glasgow Outcome Scale

\begin{tabular}{lcccc}
\hline GOS & Surgical cases & Really severe & Mild/moderate & Mistakenly severe \\
\hline 1 & $104 / 287$ & $105 / 324$ & $4 / 49$ & $1 / 48$ \\
& $(36 \%)$ & $(32 \%)$ & $(8 \%)$ & $(2 \%)$ \\
2 & $12 / 287$ & $7 / 324$ & $0 / 49$ & $0 / 48$ \\
& $(4 \%)$ & $(2 \%)$ & $(0 \%)$ & $(0 \%)$ \\
3 & $34 / 287$ & $41 / 324$ & $(6 \%)$ & $2 / 48$ \\
4 & $(12 \%)$ & $(13 \%)$ & $13 / 49$ & $(4 \%)$ \\
5 & $40 / 287$ & $45 / 324$ & $(27 \%)$ & $9 / 48$ \\
& $(14 \%)$ & $(14 \%)$ & $29 / 49$ & $(19 \%)$ \\
& $97 / 287$ & $126 / 324$ & $(59 \%)$ & $36 / 48$ \\
\end{tabular}




\section{STOCCHETTI ET AL.}

uation is also indispensable in clinical trials, which require the fulfillment of strict inclusion criteria.

The importance and the difficulties of reliable neurological assessment after TBI are obvious, but they have rarely been discussed in the literature. Marion published the results of a survey in which neurosurgeons and emergency physicians from 15 U.S. centers answered multiple-choice questions. The most frequent answer that attending neurosurgeons gave to the studied question"When do you test patients who received neuromuscular paralyzing agents or sedation prior to arrival at your trauma center?"-was that they used the pre-hospital GCS score, obtained before medications were administered (Marion and Carlier, 1994). Given the high rate of intubation and problems related to proper assessment of eye opening, the authors concluded that "there was substantial evidence that the GCS motor score was more important than either of the other two components in predicting the severity of neurologic injury and outcome for patients with severe head injuries."

In a more recent paper, the possible effect of inaccurate GCS scoring due to sedation on other indexes was studied in a large set of patients admitted to 22 Scottish units. Clinicians felt unable to assess the GCS in approximately half the patients; the proportion of patients sedated was $50 \%$ on average. The authors dealt with the evidence that the use of sedative drugs precluded accurate GCS assessment during the first $24 \mathrm{~h}$ in most cases (Livingston et al., 2000). Dealing with posttraumatic subdural hematomas, Servadei et al. (1998), underlined the importance of accurate and repeated GCS ratings, and advocated the avoidance of long-lasting sedatives and paralyzing medications.

Since traumatic brain lesions can evolve, with further neurological impairment, any change occurring between the accident scene and the hospital has to be detected accurately. To make the situation even more complex, neurological responses after TBI can vary over time for several reasons. Trauma is frequently associated with intoxication by alcohol or drugs; in the setting of a U.S. urban trauma center, $>74 \%$ of trauma patients tested positive for illicit or prescription drugs in their blood (Lindenbaum et al., 1989). A review of studies evaluating the coexistence of alcohol intoxication and TBI found a rate of intoxication at the time of injury of 36-51\% (Corrigan, 1995). It was not the policy of the hospitals participating in this study to measure the plasma concentrations of alcohol or drugs, so this information was not collected.

Neurological evaluation is necessary for decision-making, but it must be combined with the CT scan findings. In our series, based on CT findings, 304 patients underwent urgent evacuation of intracranial masses. It is pos- sible, or even likely, that for a proportion of them neurological evaluation was biased by factors such as sedation and intubation, but the evidence of masses requires special consideration. It is not prudent to suspect that a severe neurological deficit can be ascribed to sedation if the CT scan shows an overwhelming intracranial lesion (in our series, $68 \%$ of surgical cases had compressed cisterns). For this reason we have chosen to separate these cases from the group in which MS could be suspected for decision-making.

The 449 non-surgical cases included various subgroups. Fifty-five patients defined mild/moderate TBI were clearly not severe, remaining capable of obeying commands in all the neurological evaluations. Among the remaining 394 cases, it was our hypothesis that some TBI might appear severe even though the patient had not suffered major brain damage. In order to identify these mistakenly severe cases, we selected patients who appeared incapable of obeying commands at some evaluation point, but who showed prompt improvement after only a short stay in the ICU. Their clinical course was not obviously benign: six cases experienced hypoxia at the accident scene, 10 had hypotension, and 32 had extra-cranial lesions. They appeared severe as regards their total GCS: $48 \%$ at the accident scene and subsequently the majority of the MS cases had GCS of $\leq 8$. The motor response was $<6$ for the majority of cases at every evaluation point. In many centers they would therefore have qualified for ICP monitoring and could have been included in most clinical trials on neuroprotection for severe head injury. It is very doubtful, however, that they would have benefited from aggressive intensive care, ICP monitoring, and any neuroprotective agent, since they soon regained consciousness and were discharged from the ICU in a few days-in fact, $36 \%$ on the day after injury.

It is important, therefore, to separate these cases from the really severe ones, so we analyzed the main features that distinguished the MS cases. More than $90 \%$ of MS cases were classified as Diffuse Injury I or II at the qualifying CT scan and had better motor, verbal, and ocular responses at all time points than RS patients. Accordingly, their pupils were less frequently abnormal. All these data indicate less severe brain damage, both structural and functional. In contrast, patients classified as RS showed substantial brain damage in the CT scan, worse neurological presentations at every time point, longer LOS, and worse outcome.

The bivariate analysis confirmed significant differences for nine parameters, including age, hypoxia, hypotension, and extra-cranial injuries: the MS patients were younger, had fewer associated injuries, and were less frequently hypoxic and hypotensive. When all nine 


\section{INACCURATE EARLY NEUROLOGICAL ASSESSMENT IN HEAD INJURY}

parameters were entered in a statistical model, logistic regression identified age of $<40$ years, the CT scan diagnosis, and the motor and verbal components of the GCS as independent predictors. The relative weight of these features was substantial, as illustrated by the results. The odds ratios indicate, for instance, that the risk of being misclassified increases 4.2 times if the motor response is greater than 4 , and 6.4 times if the verbal response is greater than 2. The combination of these features gives a strong probability $(75 \%)$ of identifying MS cases. The model seems robust, as indicated by the good level of calibration and discrimination. Extension of these results to the real population, however, requires caution because of the relatively large confidence intervals for the estimated odds ratios, on account of the size of our sample.

Contrary to expectations, sedation and intubation were not predictors of MS. We believe, however, that this result does not rule out the influence of sedation and intubation on the over-estimation of neurological severity. The statistics indicate that there is no difference between the rate of intubation-sedation for MS and RS, but the majority of both MS (88\%) and RS $(85 \%)$ was either intubated and/or sedated, so a higher rate in one group was hard to detect. We found that MS cases were less severe, and that RS experienced significantly worse damage, with a correspondingly worse outcome. In RS, therefore, we feel that the neurological presentation was consistent with the underlying lesions, while in MS there was an inconsistency between the apparent severity and the benign course. Sedation and intubation might have contributed to this discrepancy, but other confounding factors could be involved too. Some patients may simply have had cerebral concussion and their clinical course would therefore, regardless of sedation, be short and benign. Finally, a number of cases may have been intoxicated by alcohol or drugs, which we did not check.

Based on our analysis, a few basic recommendations can be proposed. First, a careful examination should be repeated after stabilization, combining the clinical data with a concomitant CT scan. In case of surgical lesions, prompt treatment is mandatory, while the non-surgical cases call for further analysis. Young patients with a negative or almost innocent $\mathrm{CT}$, who localize the painful stimulus, have a high probability of a very benign course. This probability is obviously higher if they can speak at least "inappropriate words" (GCS verbal component of $>2$ ), but in most cases the verbal response cannot be assessed. These cases would not benefit from aggressive treatment, including ICP monitoring, and are not ideal candidates for clinical trials on severe head injury. An assessment repeated after a few hours (when anesthesia, alcohol or other drugs should have cleared) would find definite improvement, and this waiting time could avoid inappropriate interventions.

In contrast, older patients with brain damage in the CT scan, and lower scores for the GCS motor and verbal components have much less chance of early improvement. Their severity will often be confirmed by pupillary abnormalities and by the combination of extra-cranial injuries and insults, such as hypoxia and hypotension. They require close monitoring and aggressive therapy, and there is very little risk of their severity being over-estimated.

\section{CONCLUSION}

Sedation and/or intubation are applied to $90 \%$ of TBI admitted to ICU in NSH. These include a certain number of non-surgical cases whose neurological severity is probably over-estimated at various consecutive neurological examinations. They have a short stay in the ICU, a very favorable outcome and do not require aggressive care. Some distinctive features are significantly correlated with the risk of misclassification. When this risk is substantial, clinical decisions should be based on further examination.

\section{ACKNOWLEDGMENTS}

The contribution of Dr. Celia Diniz-Lima in the preparation of the manuscript is gratefully acknowledged. This work was funded in part by Raggio Verde, a volunteer family association.

\section{REFERENCES}

CHESNUT, R.M., MARSHALL, L.F., KLAUBER, M.R., et al. (1993). The role of secondary brain injury in determining outcome from severe head injury. J. Trauma. 34, 216-222.

CITERIO, G., STOCCHETTI, N., CORMIO, M., and BERETTA, L. (2000). Neuro-Link, a computer-assisted database for head injury in intensive care. Acta Neurochir. (Wien.) 142, 769-776.

CORRIGAN, J. D. (1995). Substance abuse as a mediating factor in outcome from traumatic brain injury. Arch. Phys. Med. Rehabil. 76, 302-309.

LEMESHOW, S., TERES, D., KLAR, J., AVRUNIN, J.S., GEHLBACH, S.H., and RAPOPORT, J. (1993). Mortality Probability Models (MPM II) based on an international cohort of intensive care unit patients. JAMA 270, 2478-2486.

LINDENBAUM, G.A., CARROLL, S.F., DASKAL, I., and KAPUSNICK, R. (1989). Patterns of alcohol and drug abuse 


\section{STOCCHETTI ET AL.}

in an urban trauma center: the increasing role of cocaine abuse. J. Trauma 29, 1654-1658.

LIVINGSTON, B.M., MACKENZIE, S.J., MACKIRDY, F.N., and HOWIE, J.C. (2000). Should the pre-sedation Glasgow Coma Scale value be used when calculating Acute Physiology and Chronic Health Evaluation scores for sedated patients? Scottish Intensive Care Society Audit Group. Crit. Care Med. 28, 389-394.

MAAS, A.I., DEARDEN, M., TEASDALE, G.M., et al. (1997). EBIC-guidelines for management of severe head injury in adults. European Brain Injury Consortium. Acta Neurochir. (Wien). 139, 286-294.

MANLEY, G., KNUDSON, M.M., MORABITO, D., DAMRON, S., ERICKSON, V., and PITTS, L. (2001). Hypotension, hypoxia, and head injury: frequency, duration, and consequences. Arch. Surg. 136, 1118-1123.

MARION, D.W., and CARLIER, P.M. (1994). Problems with initial Glasgow Coma Scale assessment caused by prehospital treatment of patients with head injuries: results of a national survey. J. Trauma. 36, 89-95.

MARSHALL L.F., MARSHALL S.B., KLAUBER M.R., et al. (1991). A new classification of head injury based on computerized tomography. J. Neurosurg. (Suppl.) 75, 14-20.

SERVADEI, F., NASI, M.T., CREMONINI, A.M., GIULIANI, G., CENNI, P., and NANNI, A. (1998). Importance of a reliable admission Glasgow Coma Scale score for determining the need for evacuation of posttraumatic subdural hematomas: a prospective study of 65 patients. J. Trauma. 44, 868-873.
STOCCHETTI, N., FURLAN, A., and VOLTA, F. (1996). Hypoxemia and arterial hypotension at the accident scene in head injury. J. Trauma 40, 764-767.

TEASDALE, G., and JENNETT, B. Assessment of coma and impaired consciousness. A practical scale. Lancet 2, 81-84.

THE BRAIN TRAUMA FOUNDATION. (2000). Resuscitation of blood pressure and oxygenation. The American Association of Neurological Surgeons. The Joint Section on Neurotrauma and Critical Care. J. Neurotrauma. 17, 471-478.

WILSON, J.T., PETTIGREW, L.E., and TEASDALE, G.M. (1998). Structured interviews for the Glasgow Outcome Scale and the extended Glasgow Outcome Scale: guidelines for their use. J. Neurotrauma 15, 573-585.

WINCHELL, R.J., and HOYT, D.B. (1997). Endotracheal intubation in the field improves survival in patients with severe head injury. Trauma Research and Education Foundation of San Diego. Arch. Surg. 132, 592-597.

Address reprint requests to: Nino Stocchetti, M.D. Terapia Intensiva Neuroscienze Ospedale Policlinico IRCCS Padiglione Beretta Neuro Via F. Sforza, 35 20122 Milano, Italy

E-mail: stocchet@policlinico.mi.it 


\section{This article has been cited by:}

1. Dr. Stefania Mondello, Dr. Steven Robicsek, Dr. Andrea Gabrielli, Dr. Gretchen Brophy, Dr. Linda Papa , Joseph Tepas III , Dr. Claudia Robertson, Dr. Andras Buki M.D., Ph.D. , Ms. Dancia Scharf, Ms. Mo Jixiang, Ms. Linnet Akinyi , Dr. Uwe Muller , Dr. Kevin K.W. Wang , Dr. Ronald L Hayes . aII-Spectrin Breakdown Products (SBDPs): Diagnosis and Outcome in Severe Traumatic Brain Injury PatientsaII-Spectrin Breakdown Products (SBDPs): Diagnosis and Outcome in Severe Traumatic Brain Injury Patients. Journal of Neurotrauma 0:ja. . [Abstract] [PDF] [PDF Plus]

2. Marek A. Mirski, John J. Lewin, Shannon LeDroux, Carol Thompson, Peter Murakami, Elizabeth K. Zink, Michael Griswold. 2010. Cognitive improvement during continuous sedation in critically ill, awake and responsive patients: the Acute Neurological ICU Sedation Trial (ANIST). Intensive Care Medicine . [CrossRef]

3. Gustavo Petroni, Marta Quaglino, Silvia Lujan, Leandro Kovalevski, Carlos Rondina, Walter Videtta, Nancy Carney, Nancy Temkin, Randall Chesnut. 2010. Early Prognosis of Severe Traumatic Brain Injury in an Urban Argentinian Trauma Center. The Journal of Trauma: Injury, Infection, and Critical Care 68:3, 564-570. [CrossRef]

4. Linda Papa, Linnet Akinyi, Ming Cheng Liu, Jose A. Pineda, Joseph J. Tepas, Monika W. Oli, Wenrong Zheng, Gillian Robinson, Steven A. Robicsek, Andrea Gabrielli, Shelley C. Heaton, H Julia Hannay, Jason A. Demery, Gretchen M. Brophy, Joe Layon, Claudia S. Robertson, Ronald L. Hayes, Kevin K. W. Wang. 2010. Ubiquitin C-terminal hydrolase is a novel biomarker in humans for severe traumatic brain injury*. Critical Care Medicine 38:1, 138-144. [CrossRef]

5. Christian Compagnone, Domenico d'Avella, Franco Servadei, Filippo F. Angileri, Gianluigi Brambilla, Carlo Conti, Luciano Cristofori, Roberto Delfini, Luca Denaro, Alessandro Ducati, Sergio M. Gaini, Roberto Stefini, Giustino Tomei, Fernanda Tagliaferri, Giuseppe Trincia, Francesco Tomasello. 2009. PATIENTS WITH MODERATE HEAD INJURY. Neurosurgery 64:4, 690-697. [CrossRef]

6. Nino Stocchetti, Giuseppe Citerio, Andrew Maas, Peter Andrews, Graham Teasdale. 2008. Bryan Jennett and the field of traumatic brain injury. His intellectual and ethical heritage in neuro-intensive care. Intensive Care Medicine 34:10, 1774-1778. [CrossRef]

7. Kathryn E. Saatman , Ann-Christine Duhaime, Ross Bullock, Andrew I.R. Maas, Alex Valadka, Geoffrey T. Manley . 2008. Classification of Traumatic Brain Injury for Targeted TherapiesClassification of Traumatic Brain Injury for Targeted Therapies. Journal of Neurotrauma 25:7, 719-738. [Abstract] [PDF] [PDF Plus]

8. Walter Mauritz, Heinz Steltzer, Peter Bauer, Lorenz Dolanski-Aghamanoukjan, Philipp Metnitz. 2008. Monitoring of intracranial pressure in patients with severe traumatic brain injury: an Austrian prospective multicenter study. Intensive Care Medicine 34:7, 1208-1215. [CrossRef]

9. François J.A. Slieker, Erwin J.O. Kompanje, Gordon D. Murray, Juha Öhman, Nino Stocchetti, Sir Graham Teasdale, Andrew I.R. Maas. 2008. IMPORTANCE OF SCREENING LOGS IN CLINICAL TRIALS FOR SEVERE TRAUMATIC BRAIN INJURY. Neurosurgery 62:6, 1321-1329. [CrossRef]

10. Brandon P. Foreman, R Ruth Caesar, Jennifer Parks, Christopher Madden, Larry M. Gentilello, Shahid Shafi, Mary C. Carlile, Caryn R. Harper, Ramon R. Diaz-Arrastia. 2007. Usefulness of the Abbreviated Injury Score and the Injury Severity Score in Comparison to the Glasgow Coma Scale in Predicting Outcome After Traumatic Brain Injury. The Journal of Trauma: Injury, Infection, and Critical Care 62:4, 946-950. [CrossRef]

11. Jose A. Pineda, Stephen B. Lewis, Alex B. Valadka, Linda Papa , H. Julia Hannay, Shelley C. Heaton, Jason A. Demery, Ming Cheng Liu , Jada M. Aikman, Veronica Akle, Gretchen M. Brophy, Joseph J. Tepas III, Kevin K.W. Wang, Claudia S. Robertson, Ronald L. Hayes . 2007. Clinical Significance of aII-Spectrin Breakdown Products in Cerebrospinal Fluid after Severe Traumatic Brain InjuryClinical Significance of aII-Spectrin Breakdown Products in Cerebrospinal Fluid after Severe Traumatic Brain Injury. Journal of Neurotrauma 24:2, 354-366. [Abstract] [PDF] [PDF Plus]

12. Anthony Marmarou, Juan Lu, Isabella Butcher, Gillian S. McHugh, Gordon D. Murray, Ewout W. Steyerberg, Nino A. Mushkudiani, Sung Choi , Andrew I.R. Maas . 2007. Prognostic Value of The Glasgow Coma Scale And Pupil Reactivity in Traumatic Brain Injury Assessed Pre-Hospital And on Enrollment: An IMPACT AnalysisPrognostic Value of The Glasgow Coma Scale And Pupil Reactivity in Traumatic Brain Injury Assessed Pre-Hospital And on Enrollment: An IMPACT Analysis. Journal of Neurotrauma 24:2, 270-280. [Abstract] [PDF] [PDF Plus]

13. Arturo Chieregato, Ospedale M. Bufalini. 2007. Randomized clinical trial of intracranial pressure monitoring after severe head injury. Critical Care Medicine 35:2, 673-674. [CrossRef]

14. P. F. Stahel, W. Ertel, C. E. Heyde. 2005. Einfluss des Schädel-Hirn-Traumas auf Zeitpunkt und Technik der Frakturversorgung. Der Orthopäde 34:9, 852-864. [CrossRef] 